\title{
A Pneumatic Dibbling Machine for Plastic Mulch
}

\author{
M. J. Lawrence, D. R. Buckmaster, W. J. Lamont, Jr.
}

\begin{abstract}
A machine capable of placing planting holes for a wide variety of spacings in plastic mulch beds with very little physical reconfiguration was designed and tested. The three-point hitch mounted machine was demonstrated with two horticultural crops which have widely varying within-row and between-row spacing requirements: onions and potatoes. The piercing mechanisms were powered by pneumatic cylinders, and the on-board controls allowed users to adjust the number and spacing of holes. Switches enabled between-row spacing to vary by placing from one to four planting holes across a standard 76-cm (30-in.) bed. For the algorithm used, a dial was set to create the within-row spacing between 15 and $61 \mathrm{~cm}$ (6 and $24 \mathrm{in}$.). These control settings and a fixed tractor speed acted as inputs to a microprocessor which calculated hole placement frequency and initiated cylinder activation.

The machine has been in use for two planting seasons with promising results. Hole placement accuracy data were collected for both onions and potatoes. The potato tests were performed for a within-row spacing of $30 \mathrm{~cm}$ (12 in.) and produced $96 \%$ of the planting holes within $\pm 10 \%$ of the target spacing distance. The onion tests were performed for a within-row plant spacing of $15 \mathrm{~cm}$ (6 in.) and produced $98 \%$ of the planting holes within $\pm 10 \%$ of the target spacing distance.

The technology used for this research is readily available and is a viable option to accomplish numerous planting configurations with very little reconfiguration of machine components.
\end{abstract}

Keywords. Dibble, Plastic mulch, Plasticulture, Precision planting.

$\mathrm{T}$ The technology and practice of using plastics to improve horticultural crop yield is a relatively new science commonly referred to as plasticulture. The discovery and development of the polyethylene polymer in the late 1930s, and its subsequent introduction in the early $1950 \mathrm{~s}$ in the form of plastic films, mulches, and drip-irrigation tubing and tape, revolutionized the commercial production of selected vegetable crops and gave rise to plasticulture (Lamont, 1996). Plasticulture research and documentation largely focus on the impact of plastics on horticultural crop plants and their associated yields rather than the science behind machinery-designed specifically for the planting and harvesting processes. Plastic mulches covering raised beds in which crops are planted are one form of plasticulture. A primary challenge in establishing crops in plastic mulch is the need to perforate the plastic to enable either seed or transplants to be placed in the soil (Bryan and Shaw, 1987). This very statement was cited in a more recent publication by Orzolek (1996) indicating that 11 years had passed with little significant progress in this particular procedure. The study and improvement of this process using an electro-pneumatic system was the focus of this research.

Submitted for review in March 2006 as manuscript number PM 6552; approved for publication by the Power \& Machinery Division of ASABE in March 2007.

The authors are Matthew J. Lawrence, ASABE Member Engineer, Graduate Student, Agricultural and Biological Engineering Department, Pennsylvania State University, University Park, Pennsylvania; Dennis R. Buckmaster, ASABE Member Engineer, Associate Professor, Department of Agricultural and Biological Engineering, Purdue University, West Lafayette, Indiana; and William J. Lamont, Professor, Department of Horticulture, Pennsylvania State University, University Park, Pennsylvania. Corresponding author: Matthew J. Lawrence, 249 Agricultural Engineering Bldg., University Park, PA 16802; phone: 814-863-8233; fax: 814-863-1031; e-mail: mj1145@psu.edu.

\section{Design Considerations of Plastic Mulch Preparation}

There are two major design considerations to place planting holes successfully and accurately in plastic mulch beds: (1) crop spacing within the plastic mulch bed, and (2) measurement of travel distance.

\section{Crop Spacing within the Plastic Mulch Bed}

There have been several methods developed and researched to punch planting holes in a plastic mulch bed prior to planting (Jafari and Fornstrom, 1972; Heinemann et al., 1973; Herzoni et al., 1986; Munilla and Shaw, 1987). The primary reason for this was that many horticultural crops require different within-row and between-row spacings as well as hole depth within the bed. Table 1 (Lamont, 1996) details some of these spacing requirements for different crops that are common in plastic mulch beds.

Machines incapable of adjusting to different hole placement specifications were limited to few crops. The variability of within-row and between-row spacing (fig. 1) requirements for these different crops illustrates the need for a hole placement machine with the capability to easily vary hole spacing and depth for different crops. This was a major limitation to the designs found in the literature.

\section{Measurement of Travel Distance}

Consistent spacing of planting holes requires synchronization of forward speed and hole placement activation. This synchronization was accomplished using an onboard microprocessor equipped with an internal timer. Travel distance was determined by integrating the forward speed over a known time interval. Forward speed was fixed and determined by performing an initial calibration run with the towing tractor. 
Table 1. Plant spacing for different plasticulture crops (Lamont, 1996).

\begin{tabular}{|c|c|c|c|}
\hline \multirow[b]{2}{*}{ Crop } & \multicolumn{2}{|c|}{ Within-row Spacing, cm (in.) } & \multirow{2}{*}{$\begin{array}{c}\text { Between-row Spacing on } \\
\text { Plastic Beds, cm (in.) }\end{array}$} \\
\hline & Single Row & Double Row & \\
\hline $\begin{array}{l}\text { Cucumber } \\
\text { (pickles) }\end{array}$ & $30-46(12-18)$ & $23-46(9-18)$ & $30-36(12-14)$ \\
\hline Onion & - & $10-15(4-6)$ & $10-25(4-10)$ for $3-6$ rows \\
\hline Pepper & $30-41(12-16)$ & $30-41(12-16)$ & $30-36(12-14)$ \\
\hline Tomato & 46-61 (18-24) & - & - \\
\hline Watermelon & $61-122(24-48)$ & - & - \\
\hline Potato & - & $15-30(6-12)$ & $46(18)$ \\
\hline
\end{tabular}

\section{Mechanization of Plastic Mulch Preparation}

Over the past three decades, there have been several documented attempts to mechanize not only the planting hole placement process, but also to mechanize seeding or transplanting. Experimental machines using pneumatic, electromagnetic, cam-activated, and wheel-type systems for hole placement have been developed.

Heinemann et al. (1973) developed an experimental machine to place holes in soil using a pneumatic cylinder. The pneumatic cylinder was mounted vertically and was placed behind a ground-driven wheel. The wheel was configured with magnets evenly spaced around its perimeter. The magnets periodically activated a reed switch, thereby opening the air valve and driving the cylinder rod into the soil. The spacing of the magnets on the ground-driven wheel controlled the planting hole spacing.

Herzoni et al. (1986) explored a pneumatic perforation method using a power take-off (PTO) driven compressor and a double acting cylinder. In this design, the cylinder was activated with a cam operated switch. Herzoni et al. (1986) also reported the only research found using an electromagnetic actuator. The electromagnet used the 12-V DC battery

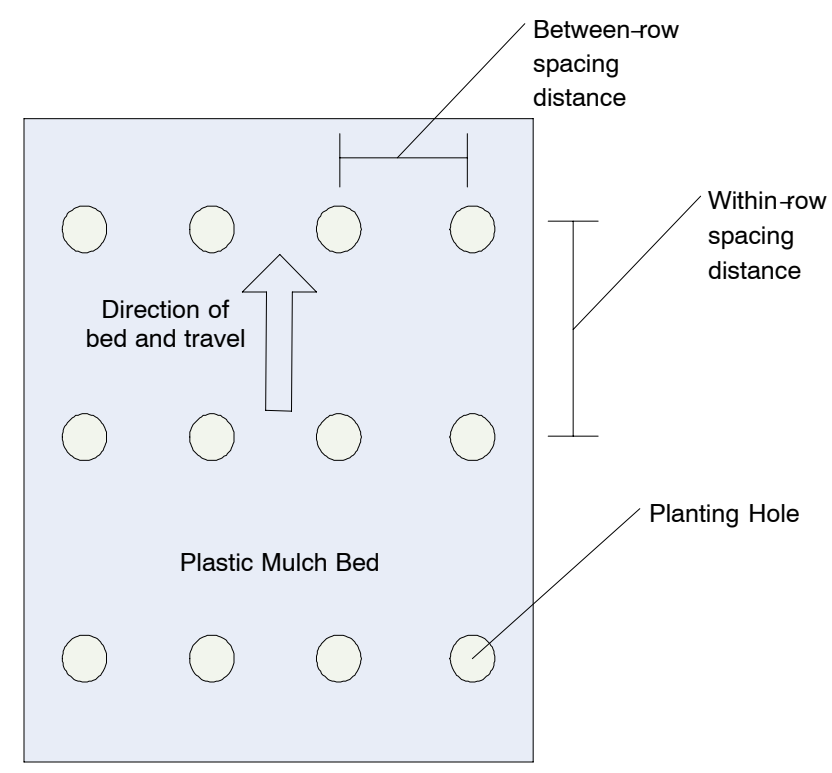

Figure 1. Top view of plastic mulch bed with within-row and between-row spacing defined. on the tractor to power the piercing mechanism, and, in the view of the authors, was the least successful of their three approaches: pneumatic, electromagnetic, and cam-activated. As with their pneumatic piercing mechanism, the cylinder was activated with a cam-operated switch. The third and final test performed by Herzoni et al. (1986) was a mechanical solution utilizing a cam mechanism directly driven by the ground wheels on the device. Munilla and Shaw (1987) designed a cam-operated high-speed dibbling transplanter. This design not only placed a hole in the soil, but it also transplanted a seedling. These researchers designed dibble buckets attached to arms extending from a hydraulically driven cam. As the cam rotated, the dibble bucket formed a hole in the soil and deposited the transplant. The spacing of the perforations in the soil was not only dependent on the rotational speed of the cam but also on the forward speed of the tractor.

The wheel-type method of placing holes in plastic mulch is more common than those previously discussed. With this method, a cylinder with spikes fixed around the perimeter is rolled along the plastic mulch bed. As the drum rotates, the spikes puncture holes in the plastic mulch, and create cavities in the soil to accommodate seed placement (Glancey, 2003). The work of Jafari and Fornstrom (1972) was an early design of a precision punch planter using the wheel-type design to place sugar beet seeds in soil. They created and tested a machine design utilizing a 51-cm (20-in.) diameter punching wheel: a wheel with cones permanently attached to the periphery. This system attains consistent spacing, however, with the wheel-type solution; the placement of the hole in the plastic is not a vertical procedure. The spike attached to the wheel tears the plastic in front of the hole upon entry because the spike must roll over the plastic before the vertical hole is placed. Similarly, the spike tears the plastic behind the hole upon exiting from the plastic mulch as the spike rolls out. The problem of tears in the plastic mulch may be compounded by wind effects. Also, poor hole cutting can lead to tearing of the plastic from wind as reported by Bryan and Shaw (1987).

The rate of plastic mulch adoption by growers has increased since it became available and is still increasing. However, the mechanization of the planting processes has not advanced accordingly. The concept of punch seeding has appealed to agricultural engineers and agronomists for about three decades, but no machines of this type are widely used (Debicki and Shaw, 1996). Machines to automate the procedures in plastic mulch planting have been designed and do exist. However, a common thread connects all these machines: no design was easily adjustable to accommodate different crop planting specifications.

Plastic mulch with pre-punched hole configurations is available; however, it does not offer flexibility in plant spacing. Furthermore, the task of forming planting holes in the soil still remains after installing pre-punched plastic mulch.

This research was conducted to determine if a single machine could accurately place planting holes for crops with different plant spacings with no physical reconfiguration of the machine required. Onions and potatoes were selected as test crops. Onions were first selected because they have the greatest population density and therefore would pose the greatest challenge for a machine of this type. Potatoes were selected because their within-row and between-row spacings are different from onions. 


\section{ObJectives}

The primary objectives of the research were to:

- Develop a computer simulation model to predict system air consumption to punch holes for onions and potatoes with crop selection and forward speed as inputs and pneumatic system specifications as outputs.

- Design and construct a 4-hole punch machine using the computer simulation model to specify the pneumatic system.

- Determine the performance characteristics of the machine using plastic mulch beds and evaluate hole placement accuracy.

\section{Methods ANd Materials}

The machine developed (fig. 2) consisted of two major components: an electro-pneumatic device that attached to the rear three-point hitch of a tractor and an air compressor mounted to the front of the tractor. The air compressor was powered by the tractor's hydraulic system. The pneumatic and control systems as well as a test procedure are discussed in this section.

\section{The Pneumatic System}

The pneumatic system was modeled using a spreadsheet prior to construction. The goal of the model was to predict compressor specifications given the following inputs: cylinder size, cylinder number, implement speed, operating air pressure, and within-row spacing. The spreadsheet model can be found in a research thesis (Lawrence, 2004). The machine was fitted with a 1.0-standard $\mathrm{m}^{3} / \mathrm{min}$ (36-standard $\mathrm{ft}^{3} / \mathrm{min}$.) air compressor. The air supply line that ran from the compressor to the valve manifold had an inside diameter of $1.3 \mathrm{~cm}$ (0.5 in.). A coalescing filter was added to prevent the accumulation of water in the system. The air compressor was driven using a $20-\mathrm{cm}^{3} / \mathrm{rev}\left(1.2-\mathrm{in} .^{3} / \mathrm{rev}\right)$ hydraulic pump and hydraulic connections on the tractor.

Cylinder bore size was a function of two inputs: operating air pressure and soil penetration force requirements. The operating pressure was set to a typical pneumatic system (690 kPa or $100 \mathrm{psi})$. At this air pressure, a 3.8-cm (1.5-in.) bore cylinder could generate $790 \mathrm{~N}(180 \mathrm{lb})$ of force. This cylinder bore diameter was based on the work of Molin and

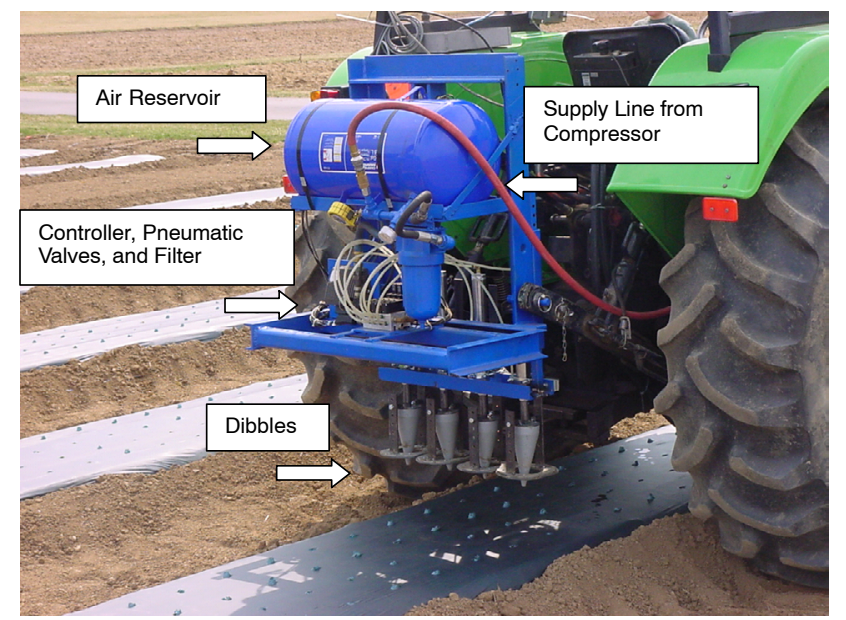

Figure 2. Fully assembled machine frame with electropneumatic components.
Bashford (1996). Their research simulated field working conditions in a laboratory to evaluate penetration forces required to pierce soil at different moisture levels and bulk densities. The cylinder stroke length was $25 \mathrm{~cm}$ (10 in.) and was selected so the dibble was at least $10 \mathrm{~cm}$ (4 in.) off of the plastic mulch bed when fully retracted.

Because manual plant placement or machine "feeding" is a relatively slow process, it is not necessary that the machine place onion or potato planting holes at high forward speeds. To plant onions with a within-row spacing of $15 \mathrm{~cm}$ (6 in.) at $3.2 \mathrm{~km} / \mathrm{h}$ ( $2 \mathrm{mph})$, a seemingly slow forward speed, all 4 cylinders on a 4-row machine would have to extend and retract at $6 \mathrm{~Hz}$. Similarly, when planting potatoes with a within-row spacing of $30 \mathrm{~cm}$ (12 in.), 2 cylinders would have to extend and retract at $3 \mathrm{~Hz}$. These cycle frequencies would not be possible using low-cost pneumatic components. Therefore, simulations used to select pneumatic components were restricted to situations in which the pneumatic cylinders actuated at $2 \mathrm{~Hz}$ or slower which was the practical limit of valve response.

The pneumatic system schematic is shown in figure 3 . The pneumatic line from the compressor to the regulator had an inside diameter of $13 \mathrm{~mm}$ (0.5 in.) and a length of $7.6 \mathrm{~m}$ $(25 \mathrm{ft})$. All other lines shown had an inside diameter of $6 \mathrm{~mm}$ (0.25 in.) and a length of about $0.5 \mathrm{~m}$ (20 in.). The air cylinders were arranged vertically on a head. The cylinders were fitted with adjustable "shoes" (fig. 4) that limited dibble penetration to accurately control hole depth.

A conical dibble was affixed to the rod ends of each cylinder to pierce the plastic mulch and shape the soil. The conical shape allowed the dibble to create a small planting hole at shallow planting depths (for onions) and a larger hole at deeper depths (potatoes, tomatoes, etc.). It also created the same orientation hole if the cylinder rod rotated. The dibbles were constructed by turning a 7.6-cm (3-in.) diameter solid rod of PVC material down on a lathe. The dibbles were $15 \mathrm{~cm}$ (6 in.) in length and had a cone angle of $14^{\circ}$. Threaded metal inserts were placed in the dibble to attach them to the cylinder rod ends and prevent wear. The cylinders were mounted across the head at $15-\mathrm{cm}$ (6-in.) intervals. Given a standard $76-\mathrm{cm}$ (30-in.) bed width, this spacing provided the flexibility to achieve the between-row spacing requirements for onions, potatoes, and other crops as shown in table 1.

\section{Control System}

Crop spacing selection and forward speed were critical inputs to the cylinder actuation and hole placement processes. Therefore, a control system was added that would accept these inputs from an initial calibration run and onboard controllers to produce the output of cylinder actuation. A Parker IQAN TOC8 controller, a microprocessor specifically designed for outdoor applications (Parker Hannifin Corp., 2003 http://www.iqan.com) was used. The TOC8 was capable of receiving 10 inputs and delivering 8 outputs. Among these inputs, the TOC8 could receive 4 frequency inputs; all other inputs had to be analog or digital. The output capability of the TOC 8 consisted of 6 digital/PWM outputs and 2 dual current outputs. The TOC8 also contained an internal timer with a resolution of 20 to $100 \mathrm{~ms}$. This internal

timer was used to control the interval between cylinder extension activations.

All programming of the TOC8 was done via an accompanying software package, IQAN Develop, which ran under 


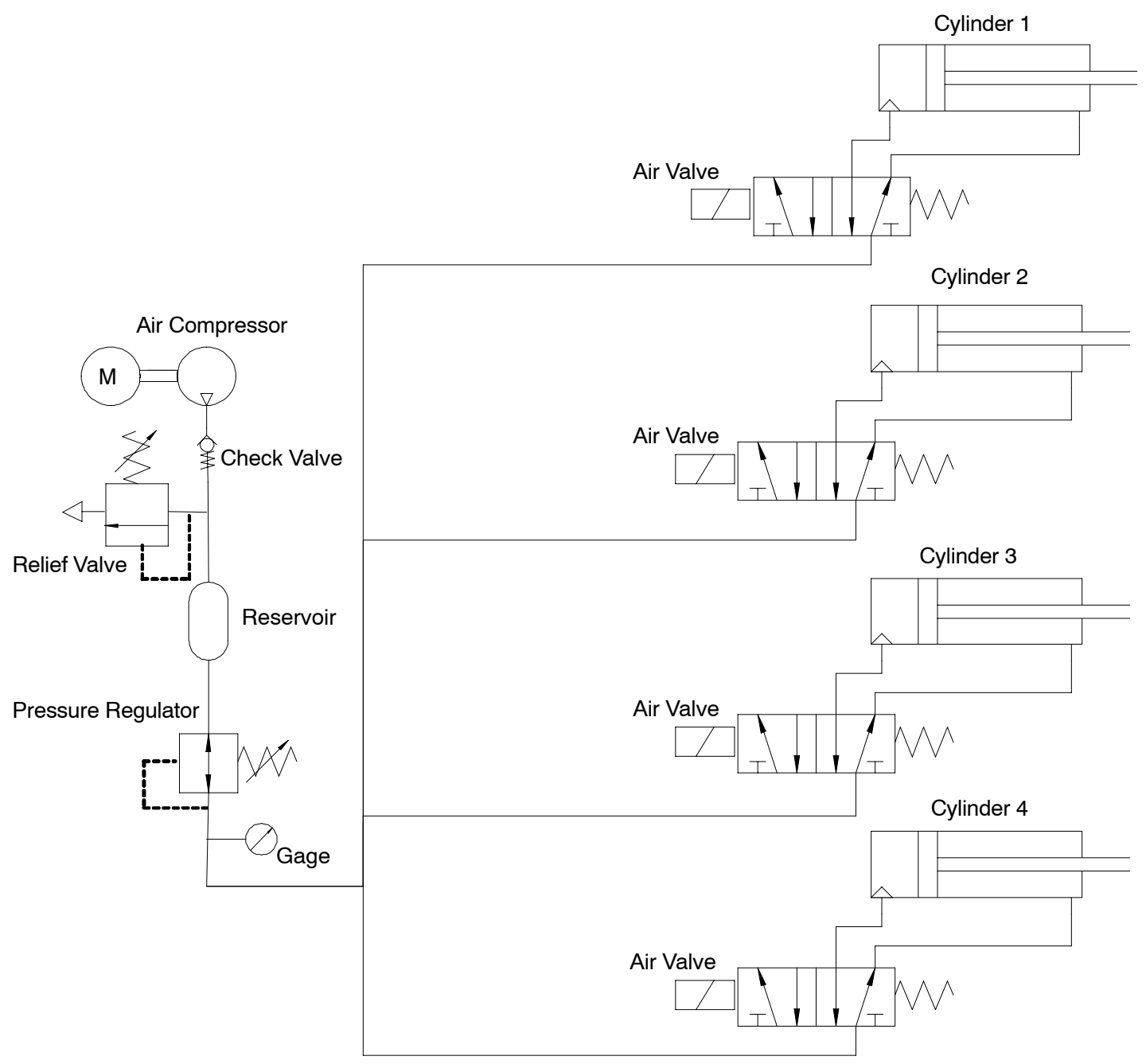

Figure 3. The pneumatic system schematic.

Microsoft Windows (Parker Hannifin Corp., 2003). The control algorithm was loaded to the TOC8 via a serial connection from a computer. Additionally, the software package was used in conjunction with a connected computer during

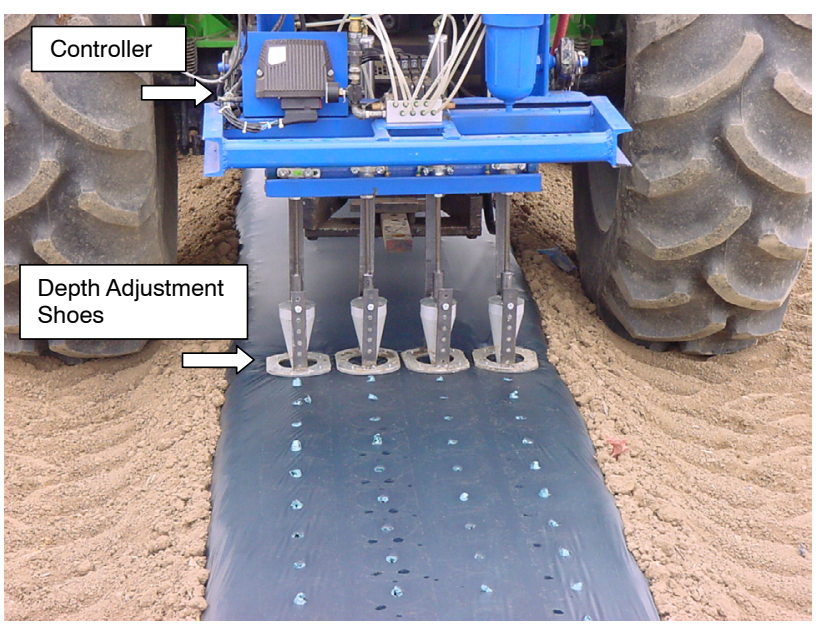

Figure 4. Pneumatic cylinder head with depth adjustment shoes prepared accurate planting holes in three dimensions on the $76-\mathrm{cm}(30$-in.) wide bed. machine operation to view real-time status of inputs, outputs, and calculation values to assist in troubleshooting.

Forward speed was determined and entered to the TOC8 after an initial calibration run. The initial calibration run was a timed run performed in the field to be planted. This took into account current field conditions. A distance of $31 \mathrm{~m}$ $(100 \mathrm{ft})$ was measured in the field and the time to travel that distance was recorded. Careful consideration was taken to ensure that the same gear and engine rpm was used during the calibration run and planting. All tests were run at an engine speed of $1500 \mathrm{rpm}$ and in the lowest gear. The lowest speed capable with the test tractor at this engine speed was $0.42 \mathrm{~km} / \mathrm{h}(0.26 \mathrm{mph})$. Initially, the towing tractor was outfitted with a radar speed sensor which acted as an input to the TOC8 controller, however, the sensor was removed, as it was incapable of providing accurate readings at speeds less than $0.63 \mathrm{~km} / \mathrm{h}(0.39 \mathrm{mph})$.

The within-row and between-row spacing input was provided through a control box mounted to the frame of the machine. The control box contained 4 cylinder switches, 1 "pause" switch, and a within-row spacing dial potentiometer. The dial position controlled within-row spacing linearly between a minimum of $15 \mathrm{~cm}(6 \mathrm{in}$.$) and a maximum of 61 \mathrm{~cm}$ (24 in.). Moving any number of the cylinder switches to "enable" allowed those enabled cylinders to actuate at intervals 
corresponding to the dial position. The "pause" switch returned all cylinders to the retracted position and deactivated cylinder actuation. This switch was used at the end of rows or during transport. Wiring and control algorithm details can be found in a research thesis (Lawrence, 2004).

\section{Machine Test and Data Collection}

The machine was field tested in plastic mulch covered beds. The beds were the standard 76-cm (30-in.) width; tests were performed on 4-mil black plastic mulch. Data collection occurred in the spring of 2006, and three 91 hole test runs were completed for each crop configuration. Ninety-one holes for each test ensured that a statistically significant conclusion could be drawn regarding the machine's accuracy based on a statistical tolerance interval.

The onion hole placement tests were run with all four cylinders enabled and a within-row spacing of $15 \mathrm{~cm}$ ( $6 \mathrm{in}$.). The potato hole placement tests were run with two cylinders enabled and a within-row spacing of $31 \mathrm{~cm}$ (12 in.). The primary goal of the testing was to determine the within-row spacing accuracy.

For each test, the within-row spacing was set, and the appropriate cylinders were enabled. The towing tractor was then placed in motion, the "pause" switch was disabled, and the test commenced. When at least 91 holes were placed, the tractor was stopped. The hole spacings were measured from the leading edge of a hole to the leading edge of the next hole with a tape measure and then recorded.

During hole placement, the tractor engine speed was held at $1500 \mathrm{rpm}$ (the engine speed held during the speed calibration run). Cylinder actuation was initiated using the internal timer of the TOC 8 controller. The onboard potentiometer was used to set the time between cylinder actuation. All enabled air cylinders were activated simultaneously. At a constant forward speed, increasing the time between cylinder actuation increased the distance between planting holes.

\section{Results AND Discussion Pneumatic System Modeling}

The pneumatic system was modeled using a spreadsheet prior to construction and can be found in a research thesis (Lawrence, 2004). Figure 5 shows the air requirement for a single, double, and quadruple row scenario with $5.1 \mathrm{~cm}(2 \mathrm{in}$.) within-row spacing intervals between 10 and $61 \mathrm{~cm} \mathrm{(4} \mathrm{and}$ 24 in.). For example, when placing four onion planting holes across the bed every $15 \mathrm{~cm}$ (6 in.) the system required about

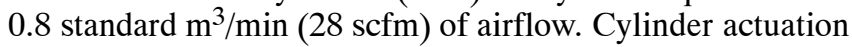
frequency, and, therefore, air demand, changes as forward speed changes. The free air demand depicted in figure 5 is accurate only for the forward speed of $0.42 \mathrm{~km} / \mathrm{h}(0.26 \mathrm{mph})$.

Compressors, particularly in mobile situations where a substantial air tank is impractical, should be sized for peak steady-state usage conditions. Of the two crop scenarios tested, maximum air usage occurred when planting onions at a between-row and within-row spacing of $15 \mathrm{~cm}(6 \mathrm{in}$.). Assuming a travel speed of $0.42 \mathrm{~km} / \mathrm{h}(0.26 \mathrm{mph})$, a compressor with a minimum rating of 0.8 standard $\mathrm{m}^{3} / \mathrm{min}(28 \mathrm{scfm})$ was recommended. Lawrence (2004) computed compressor flow rate specifications based on a number of crop and speed scenarios and recommended reasonable pneumatic systems. Additionally, a reduction of air usage is possible with the

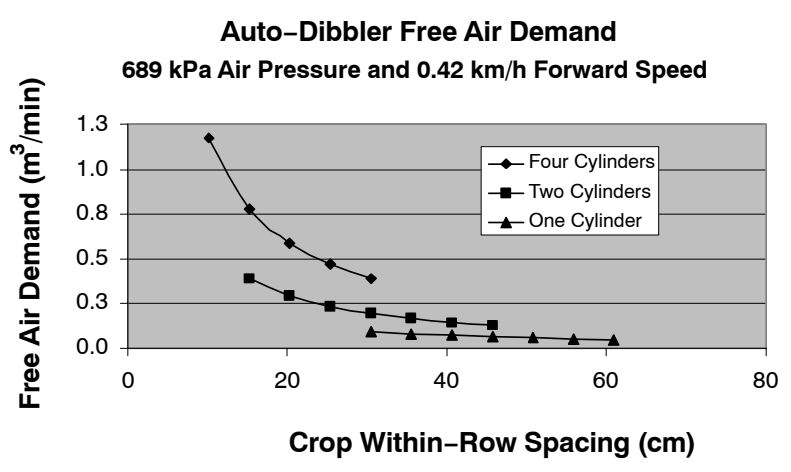

Figure 5. Air demand for different planting hole configurations with $3.8-\mathrm{cm}(1.5-\mathrm{in}$.) bore and $25-\mathrm{cm}(10$-in.) stroke air cylinders at a forward speed of $0.42 \mathrm{~km} / \mathrm{h}(0.26 \mathrm{mph})$.

introduction of a dual pressure pneumatic system (Lawrence, 2004).

\section{Machine ACCuracy}

The accuracy goal for the machine was to place $90 \%$ of holes within $\pm 10 \%$ of the within-row spacing target. For example, for a successful potato planting hole test run with a $30 \mathrm{~cm}$ (12 in.) within-row distance, acceptable spacing could range from 27 to $33 \mathrm{~cm}$ (11 to $13.2 \mathrm{in}$.). The accuracy goal was attained for all three potato tests. Of the 273 potato spacings measured and recorded, the distance was within $\pm 10 \%$ of the target distance $96 \%$ of the time. The mean potato spacing was $30 \mathrm{~cm}$ (12 in.).

The closer spacing of onions resulted in a smaller distance variation allowance given the same $\pm 10 \%$ of the within-row spacing constraint. However, the accuracy goal was also achieved for the three onion tests. Of the 273 onion spacings measured and recorded, the distance was within $\pm 10 \%$ of the target distance $98 \%$ of the time. The mean onion spacing was $15 \mathrm{~cm}$ (5.9 in.).

A potential source of variability in the measurements is tractor speed variation due to wheel slippage. A summary of the testing order as well as the descriptive statistics for each test are included in table 2.

\section{Planting Hole Quality}

Unnecessary tearing of the plastic during hole placement can lead to poor plant establishment, reduced weed control, and reduction in the positive effects of the plastic mulch covering. The holes placed by the dibbles designed for this machine appeared suitable for planting. All testing was performed in loam soil. Prior to testing, the soil was moistened using the drip tape irrigation present under the plastic mulch. This was important to maintain planting hole integrity after the dibble retracted from the soil. Tearing was minimal and the conical shape of the dibble left an acceptable void in the soil under the plastic mulch beds. Additionally, it was observed that the planting holes were often deeper than they were wide. For example, a potato planting hole was measured to be $10 \mathrm{~cm}$ (4 in.) deep but only $7.6 \mathrm{~cm}$ (3 in.) wide. Visual observations of potatoes grown in such holes indicated ideal conditions. The hole was sufficient for excellent plant starts, but small enough to eliminate tuber greening, weed growth, and tearing in wind. Dimensions such as these could not be achieved using wheel-type transplanters because of the rolling motion of the dibbles. 
Table 2. Hole placement accuracy summary.

\begin{tabular}{|c|c|c|c|c|c|c|}
\hline $\begin{array}{l}\text { Test } \\
\text { Run } \\
\text { No. }\end{array}$ & Crop & $\begin{array}{l}\text { Target Within- } \\
\text { row Spacing, } \\
\text { cm (in.) }\end{array}$ & $\begin{array}{l}\text { Number of Spacings } \\
\text { Within } \pm 10 \% \text { of the } \\
\text { Target Spacing } \\
\text { (out of } 91 \text { ) }\end{array}$ & $\begin{array}{l}\text { Mean Within-row } \\
\text { Spacing, } \\
\text { cm (in.) }\end{array}$ & $\begin{array}{c}\text { Standard Deviation of } \\
\text { Within-row Spacing } \\
\text { cm (in.) }\end{array}$ & $\begin{array}{c}\text { Coefficient } \\
\text { of Variability } \\
(\%)^{[a]}\end{array}$ \\
\hline 1 & Onions & $15(6)$ & 89 & $16(6.3)$ & $0.48(0.19)$ & 3.0 \\
\hline 2 & & & 87 & $15(5.7)$ & $0.58(0.23)$ & 4.0 \\
\hline 3 & & & 91 & $15(5.8)$ & $0.50(0.20)$ & 3.4 \\
\hline 4 & Potatoes & 31 (12) & 91 & $29(11.4)$ & $0.66(0.26)$ & 2.3 \\
\hline 5 & & & 84 & $30(11.8)$ & $2.1(0.84)$ & 7.1 \\
\hline 6 & & & 88 & $30(11.8)$ & $1.9(0.55)$ & 4.7 \\
\hline
\end{tabular}

[a] $\mathrm{n}=91$

The planting holes for onions were much smaller than those formed for potatoes. Onion transplants are smaller in size than seed potatoes. Therefore, they required smaller planting holes. Planting hole size was altered not by changing components, but rather by changing the penetration depth of the rod end dibbles using the adjustable shoes shown in figure 4 .

\section{CONCLUSION}

This design was the first known attempt to produce an easily adjustable machine for placing a wide range of planting hole configurations in plastic mulch. The concept of synchronizing forward speed to planting hole placement with adjustable operator controls was unique for horticultural crop planting. An operator can adjust the machine to provide a wide range of crop configurations and planting hole depths on a standard $76-\mathrm{cm}(30-$ in.) width plastic mulch bed.

The pneumatic system was modeled using a spreadsheet prior to construction. The model predicted compressor specifications given the following inputs: cylinder size, cylinder number, implement speed, operating air pressure, and withinrow spacing.

Six accuracy test runs were completed. Three test runs were performed at spacing appropriate for onions, and $98 \%$ of the planting holes were within $\pm 10 \%$ of the total target spacing. Three tests at the potato plant spacing distance produced $96 \%$ of the planting holes within $\pm 10 \%$ of the target spacing distance. All six test runs directly supported the stringent guidelines of the accuracy goal.

The machine was used in 2005 and 2006 to successfully place holes in plastic mulch for 20,000 onion transplants each year with a between-row spacing of $15.2 \mathrm{~cm}$ (6 in.) and a within-row spacing of $15 \mathrm{~cm}$ (6 in.). Additionally, 10,000 potato seed pieces were also planted each year with a betweenrow spacing of $46 \mathrm{~cm}$ (18 in.) and within-row spacing of $31 \mathrm{~cm}$ (12 in.). These successes in addition to the six test runs provided data that encouraged further study and possible production use.

\section{REFERENCES}

Bryan, H. H., and L. N. Shaw. 1987. Mechanical seeding through plastic mulch. Acta Horticulturae. 198: 101-110.

Debicki, I. W., and L. N. Shaw. 1996. Spade-punch planter for precision planting. Transactions of the ASAE 39(4): 1259-1267.

Glancey, J. L. 2003. Vegetable production machine design. In Encyclopedia of Agricultural, Food, and Biological Engineering, 1105-1115. D.R. Heldman, ed. New York: Marcel Dekker, Inc.

Heinemann, W. H. Jr., J. W. Cary, and A. E. Dilworth. 1973. Experimental machines for autodibble planting. Transactions of the ASAE 16(4): 656-659.

Herzoni, A., Y. Alper, A. Antler, and I. Wolf. 1986. Mechanization of vegetable production. Acta Horticulturae. 187: 93-98.

Jafari, J. V., and K. J. Fornstrom. 1972. A precision punch-planter for sugar beets. Transactions of the ASAE 15(3): 569-571.

Lamont, W. J. 1996. What are the components of a plasticulture system?. HortTechnology 6(3): 150-154.

Lawrence, M. J. 2004. A machine to precision punch plastic mulch. MS thesis. University Park, Pa.: Pennsylvania State University, Department of Agricultural and Biological Engineering.

Molin, J. P., and L. L. Bashford. 1996. Penetration forces at different soil conditions for punches used on punch planters. Transactions of the ASAE 39(2): 423-429.

Munilla, R. D., and L. N. Shaw. 1987. A high-speed dibbling transplanter. Transactions of the ASAE 30(4): 904-908.

Orzolek, M. 1996. Stand establishment in plasticulture systems. HortTechnology 6(3): 181-185.

Parker Hannifin Corporation. 2003. IQANdevelop User Manual. Ver. G3. Forest City, N.C.: Parker Hannifin Corp. 